11. Beems T, Menovsky $T$, Lammens $M$. Haemorrhagic colloid cyst: Case report and review of the literature. Surgical Neurology 2006 Jan; 65(1):84-86.

12. Smith WS, Matthay MA, Evidence for a hydrostatic mechanism of human neurogenic pulmonary oedema. Chest 1997; 111: $1326-1333$.

\section{Contribution of authors}

Performing the autopsy-ANV

Opinion- ANV

Writing the manuscript -ANV,CDW

Revising the manuscript- ANV,CDW

\title{
Picture story- Facial injuries in females
}

PAS Edirisinghe, Department of Forensic Medicine, Faculty of Medicine, University of Kelaniya
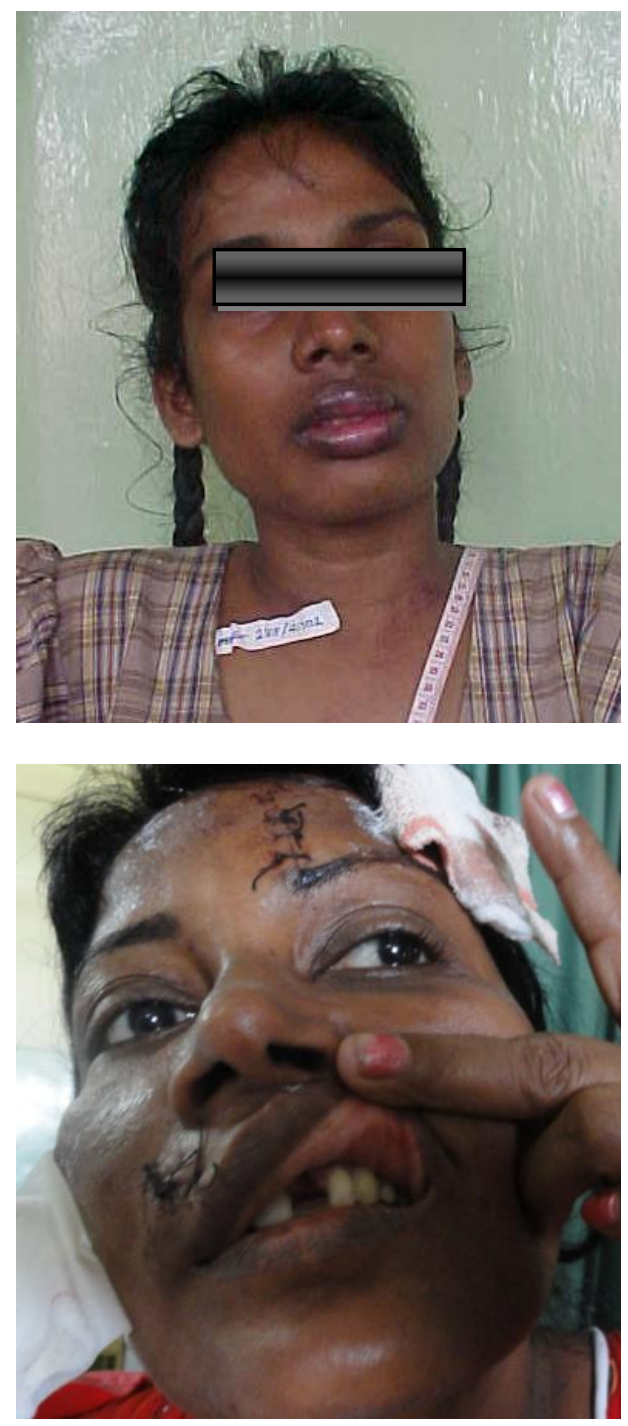

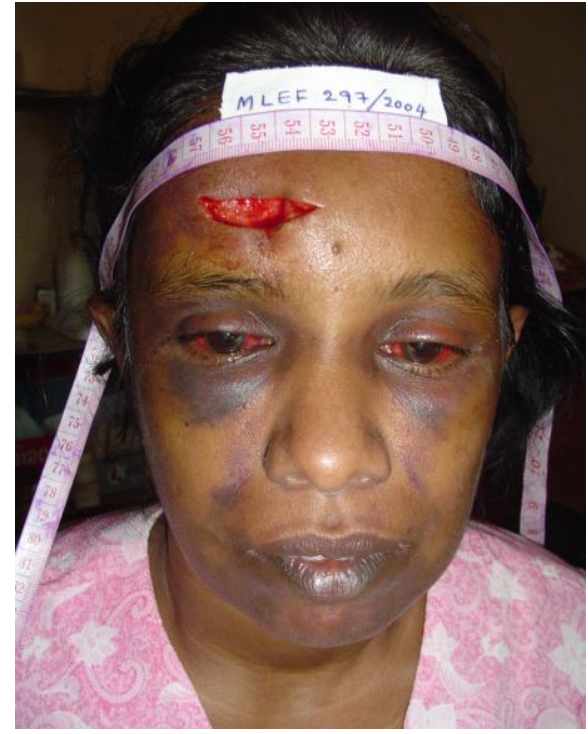

A doctor finding injuries on the face of a female has to suspect domestic violence. Although in majority of females, these injuries individually or collectively are non grievous, grievous injuries are not uncommon to find. Blunt force injuries due to slaps or fist blows to mouth and eyes are common. However, occasional cut injuries may be encountered.

A detailed history of similar episodes over the years has to be taken to understand the depth of the problem. Research indicates that the mother's experiences of domestic violence have a direct effect on children's mental health. 